\title{
THE WALKER PASS EARTHQUAKES AND STRUCTURE OF THE SOUTHERN SIERRA NEVADA*
}

\author{
By S. K. Chakrabarty and C. F. Richter
}

ON MARCh 15, 1946, a strong earthquake occurred in the Walker Pass area of the southern Sierra Nevada. This earthquake and a large foreshock and numerous aftershocks were well registered at Pasadena and its auxiliary stations in southern California. Copies of records at Boulder City and Pierce Ferry were kindly provided by the U. S. Coast and Geodetic Survey. Mr. S. T. Martner and Mr. F. E. Lehner operated the portable seismometer to record aftershocks at two localities: station No. 1 , near Isabella, at $35^{\circ} 39^{\prime} 31^{\prime \prime} \mathrm{N}$, $118^{\circ} 25^{\prime} 45^{\prime \prime} \mathrm{W}$, and station No. 2, east of Mojave, at $35^{\circ} 01^{\prime} .0 \mathrm{~N}, 118^{\circ} 01.7 \mathrm{~W}$.

There were many interruptions of recording at Haiwee, the nearest of the permanent stations; in consequence, the shocks recorded at the temporary stations 1 and 2 were not recorded at Haiwee, although times for these at several of the more distant stations are available.

Assuming that the aftershocks recorded by the portable seismometer originated at the same point as the main shock, epicenter and origin time were determined, in classwork at the California Institute of Technology, as $35^{\circ}$ $44^{\prime} \mathrm{N}, 118^{\circ} 02.5 \mathrm{~W} ; \mathrm{O}=05: 49: 36$ March 15, 1946. ${ }^{1}$ This was taken as a first approximation in the work now to be reported.

The readings used are given in tables 1 and 2 . These include all the larger shocks of the group, all those well recorded at the temporary stations 1 and 2 , and a few others selected for clear seismograms or for exceptional epicenters. Times for the main shock (no. 2) were determined independently by several workers on different occasions. Other readings, especially the times of first motion, were originally made in course of the routine laboratory work. These were checked where there appeared to be discrepancies, and altered only when examination definitely indicated error in excess of 0.2 second. Since the larger earthquakes recorded at most of the stations with such amplitudes that only the first motion and a few sharp phases can be read with confidence, seismograms of smaller shocks were reread for additional phases. Only definite wave arrivals were accepted; the readings were made without reference to expected times, but were later found to include members of the $\mathrm{P}$ and $\mathrm{S}$ groups, as well as several reflected phases.

In tables 1 and 2 each reading identified as corresponding to one of the principal phases is entered in a column with the appropriate heading. Where the observed time suggests such identification but does not closely agree with the calculated time, it is enclosed in parentheses; this does not imply any uncer-

* Manuscript received for publication October 28, 1948.

1 All times in this paper are Pacific Standard Time. For G.C.T. add 8 hours. 

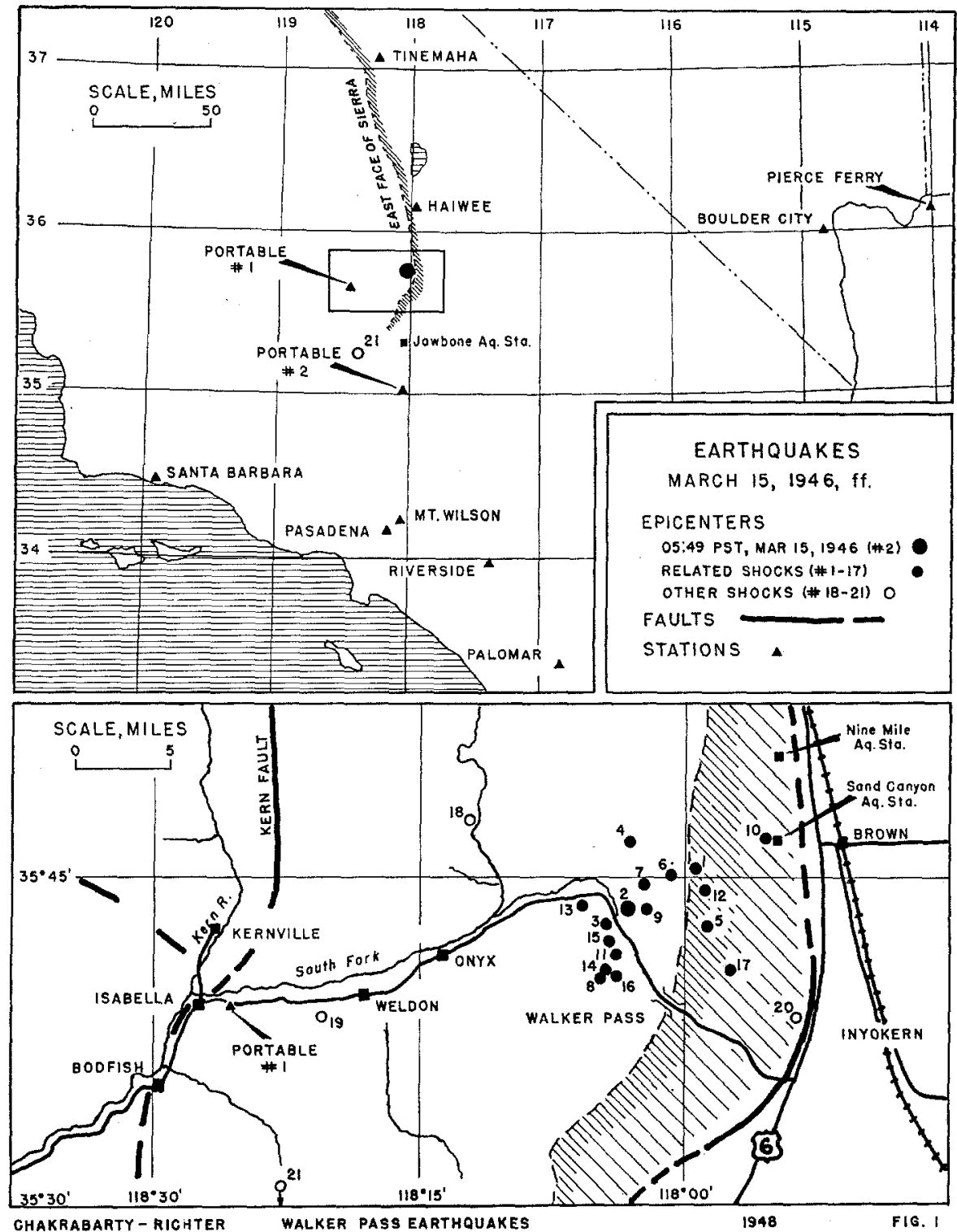

Fig. 1. Upper half, map showing the general region and seismological stations, with outline corresponding to large-scale map; lower half, large-scale map showing epicenters of the Walker Pass shock group and immediately surrounding area. 
tainty in the observation. Columns headed $R_{1}, R_{2}, R_{3}, R_{4}$ show readings referred to four reflected waves which, with modification of structure to be explained presently, correspond to those designated by Gutenberg (1944) as $\mathrm{S}_{33} \mathrm{P}, \mathrm{SP}_{18} \mathrm{P}, \mathrm{S}_{33} \mathrm{~S}$, and $\mathrm{S}_{33} \mathrm{SS}_{33} \mathrm{~S}$, respectively. Unidentified clear phases appear in columns headed $X$ and $Y$.

Not all the times of first motion for the main shock (no. 2 in the tables) are as definite as those for some of the smaller ones. This is partly due to a more gradual and complicated beginning. There is disturbance from an earthquake in South America which begins recording about two minutes earlier, with the following times of first motion:

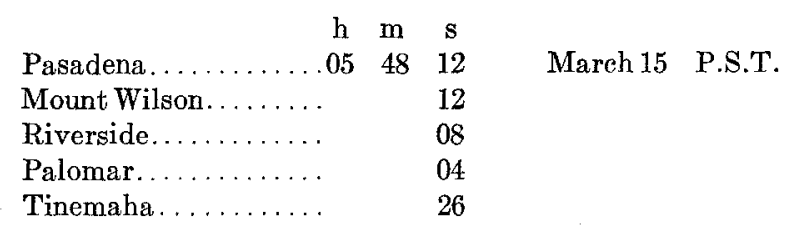

At several stations, notably at Santa Barbara, the recording lines are so confused by the preceding and following shocks that accurate reading is diffcult. At Tinemaha the galvanometer recording the vertical component was put out of action by the first shock, so that times in the next three hours can be read only from the horizontal-component seismograms.

Tables 1 and 2 also give distances calculated from the epicenters listed in table 3 , which gives final results for the individual shocks. Latitude and longitude are given as found in the final computations. These positions have been determined relatively to that given for the main shock, no. 2 , in terms of rectangular coördinates $X$ and $Y$, which are given in kilometer units. Origin times are given to the tenth of a second, and magnitudes to the tenth of a scale unit.

These epicenters were fixed by a process of successive approximations. Differences between times of the first motion at pairs of stations show systematic variations attributable to small relative displacement of the epicenters. However, a few well-recorded smaller shocks agreed closely with the main shock. All the phase readings for these were combined in a single preliminary plot, assuming the preliminary epicenter and origin time for the main shock. This plot indicated reasonably close agreement with the standard travel times worked out for the region by Gutenberg. ${ }^{2}$ At the Tinemaha station, Pn either does not arrive or is delayed; this is an effect of the "root" of the Sierra Nevada. ${ }^{3}$ However, the time of first motion is sharply recorded, and its varia-

${ }^{2}$ B. Gutenberg, "Reflected and Minor Phases in Records of Near-by Earthquakes in Southern California," Bull. Seism. Soc. Am., 34: 137-160 (1944).

'Perry Byerly and J. T. Wilson, "The Central California Earthquakes of May 16, 1933, and June 7, 1934," Bull. Seism. Soc. Am., 25: 223-246 (1935); Perry Byerly, "The Sierra Nevada in the Light of Isostasy," Bull. Geol. Soc. Am., 48:2025-2031 (1938); B. Gutenberg, "Earthquakes and Structure in Southern California," Bull. Geol. Soc. Am., 54: 499-526 (1943). 
tion with respect to that at other stations is an important datum in the next stage of investigation.

The other tabulated shocks were now located with reference to the main shock. At first, separate least-squares solutions were made, using only stations recording Pn. These stations were not well distributed in azimuth; and it appeared on examination of the remaining recorded times that the locations found in this way could not be accepted. Satisfactory results were reached by plotting the time differences against the main shock as a function of azimuth for all stations. Epicenter and origin time for the main shock were finally revised by the least-squares method on the assumption that the first motion at Haiwee is $\overline{\mathrm{P}}$; at Tinemaha, Py; and at other stations, Pn. The epicenters for the other shocks were adjusted to this, also by least-squares work.

Distances of the stations from the individual epicenters were then found, and all the readings were included in a single plot. The variation in distance from each station for the several epicenters provides extended segments of the various travel-time curves. Shocks in other parts of the general region, nos. 18-21, table 2 , were added to the study at this stage, in order to supply points in the gaps of the distance ranges.

From the data of this general plot representative travel-time curves were derived. The velocities found were so near those derived by Gutenberg for the region that his values were accepted and adjusted to the data by choice of the constant terms in the equations. The adopted times are as follows:

$$
\begin{array}{ll}
\mathrm{P}_{\mathrm{n}}-\mathrm{O}=0.124 \Delta+6.5 & \mathrm{~S}_{\mathrm{n}}-\mathrm{O}=0.225 \Delta+9.6 \\
\mathrm{P}_{\mathrm{m}}-\mathrm{O}=0.144 \Delta+3.9 & \mathrm{~S}_{\mathrm{m}}-\mathrm{O}=0.244 \Delta+6.5 \\
\mathrm{P}_{\mathrm{y}}-\mathrm{O}=0.1654 \Delta+1.5 & \mathrm{~S}_{\mathrm{y}}-\mathrm{O}=0.274 \Delta+3.0 \\
\overline{\mathrm{P}}-\mathrm{O}=0.1793 D & \overline{\mathrm{S}}-\mathrm{O}=0.3066 D
\end{array}
$$

These diverge only moderately from the Gutenberg standard times. The times of the P group correspond to a structure with thicknesses of the successive layers as $21.7 \mathrm{~km}$., $9.7 \mathrm{~km}$. and $10.7 \mathrm{~km}$. This places the Mohorovičić discontinuity at a depth of $42.1 \mathrm{~km}$. The hypocenter, as usual, is placed at the base of the uppermost (granitic) layer.

An attempt to derive the structure independently from the $S$ group of phases led to an absurdity; but calculation from the structure which fits the $\mathrm{P}$ group will represent the $\mathbf{S}$ phases within the limits of error, which are much larger than for the $\mathrm{P}$ set. Calculation based on the assumed structure represents several of the minor phases closely; the computed times for four of the reflected phases (given in tables 1 and 2 as $R_{1}, R_{2}, R_{3}, R_{4}$ ) agree more nearly with the readings than those which would be found from the Gutenberg standard curves (those designated as $\mathrm{S}_{33} \mathrm{P}, \mathrm{SP}_{18} \mathrm{P}, \mathrm{S}_{33} \mathrm{~S}, \mathrm{~S}_{33} \mathrm{SS}_{33} \mathrm{~S}$, respectively).

As an example of the closeness with which the observed times of first motion 
fit the chosen structure and velocities, we take shock no. 1, with epicenter and origin time as given in table 3 (distances from this epicenter may be found in table 1).

\begin{tabular}{|c|c|c|c|}
\hline Station & Phase & Obs. & Calc. \\
\hline Pasadena.. & Pn & 29.6 & 29.6 \\
\hline Mount Wilson $\ldots \ldots \ldots \ldots \ldots$ & Pn & 28.4 & 28.6 \\
\hline Riverside $\ldots \ldots \ldots \ldots \ldots \ldots$ & Pn & 32.8 & 32.6 \\
\hline Palomar... & Pn & 43.1 & 42.8 \\
\hline Santa Barbara. . . . . . . . . & $\operatorname{Pn}$ & 34.1 & 34.0 \\
\hline Boulder City....... & Pn & 42.8 & 43.1 \\
\hline Pierce Ferry ..... & Pn & 52.3 & 52.2 \\
\hline Tinemaha... & $\mathrm{Pm}$ & 26.4 & 26.5 \\
\hline Haiwee....... & $\overline{\mathrm{P}}$ & 9.2 & 9.5 \\
\hline
\end{tabular}

At Mount Wilson, Palomar, and Boulder City, 0.2 second has been added to the calculated time of Pn to allow for height. The difference between observed and calculated arrival time in no case exceeds 0.3 second, which is within the limits of error. For some of the smaller shocks the fit is even better.

For shocks 18-21, with epicenters remote from the main group, it appears that the Gutenberg mean travel times fit better than those here used. This suggests a local deviation from the normal thicknesses of the crustal layers, centered near that part of the southern Sierra Nevada under which the main shock originated; this is not comparable with the much larger deviation represented by the mountain "root," which lies farther north and probably east.

Shocks 19 and 21, southwest of the main epicenter, show a clear Pn at Tinemaha, so that the root does not interfere with Pn from those sources. Pn also appears in shocks 10 and 20, east of the main source. Pn is distinguishable from Pm by its longer period as well as its earlier arrival. For shock 18, to the west, $\mathrm{Pn}$ is absent at Tinemaha. This shock is peculiar in that $\overline{\mathrm{P}}$ at Haiwee and Pn at Palomar both appear to be early, whereas most of the other readings appear to be on time when compared with those of the other shocks studied.

A number of readings indicate a phase arriving a second or two earlier than Sn, with a higher apparent velocity.

The principal epicenter is exceptionally well determined. It lies 8 kilometers west of the Sierra front, which nearly coincides with the major Sierra fault. With the calculated depth of 21 kilometers, this would require a dip of $70^{\circ}$ to place the hypocenter on the fault. Such a dip would be consistent with the general curvature of the Sierra structure in this region, which is convex to the east. However, there are known active faults in the interior of the Sierra mass. The minor shocks scatter about the main epicenter, but there seems to be a concentration suggesting an active structure trending NNE-SSW. 


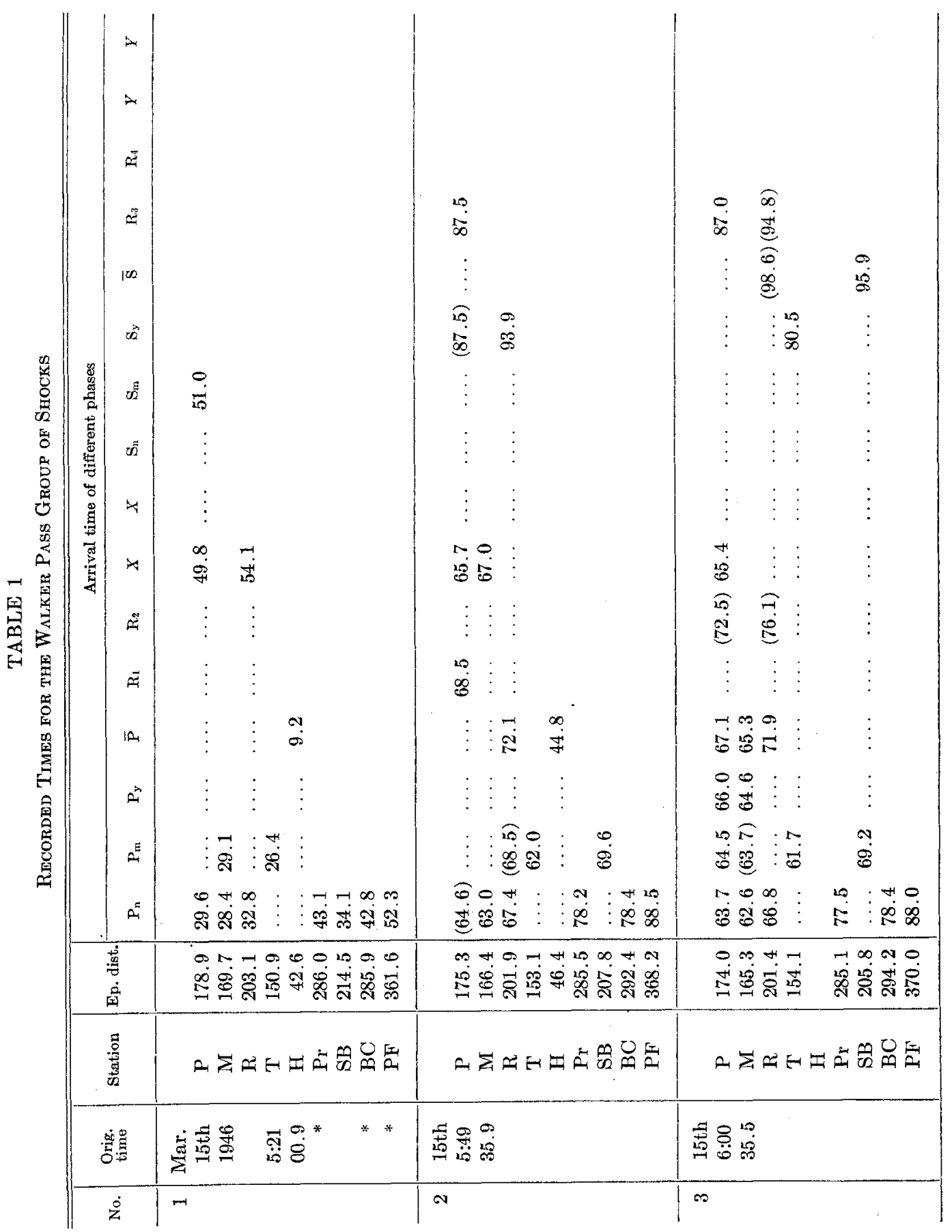


THE WALKER PASS EARTHQUAKES

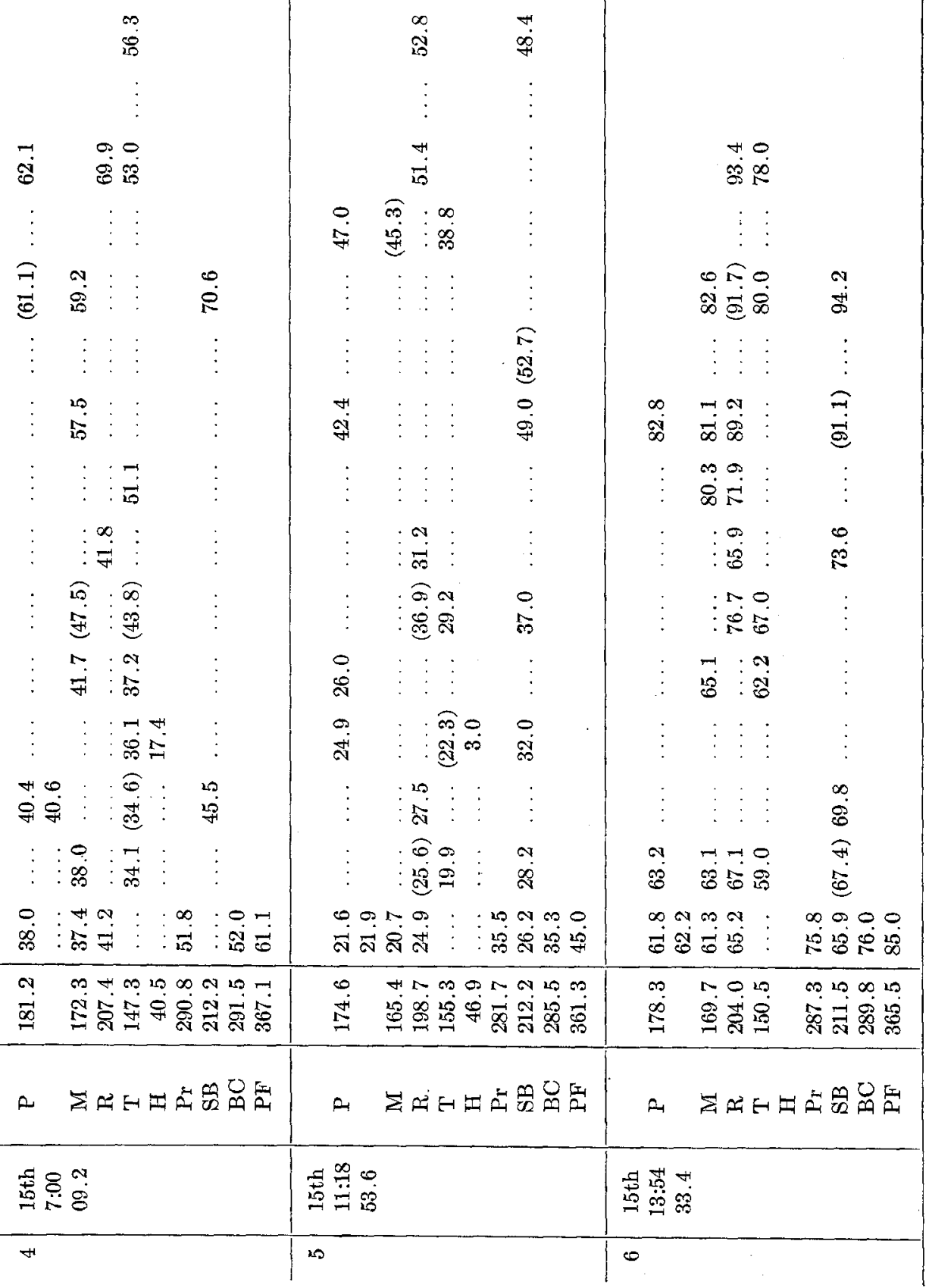




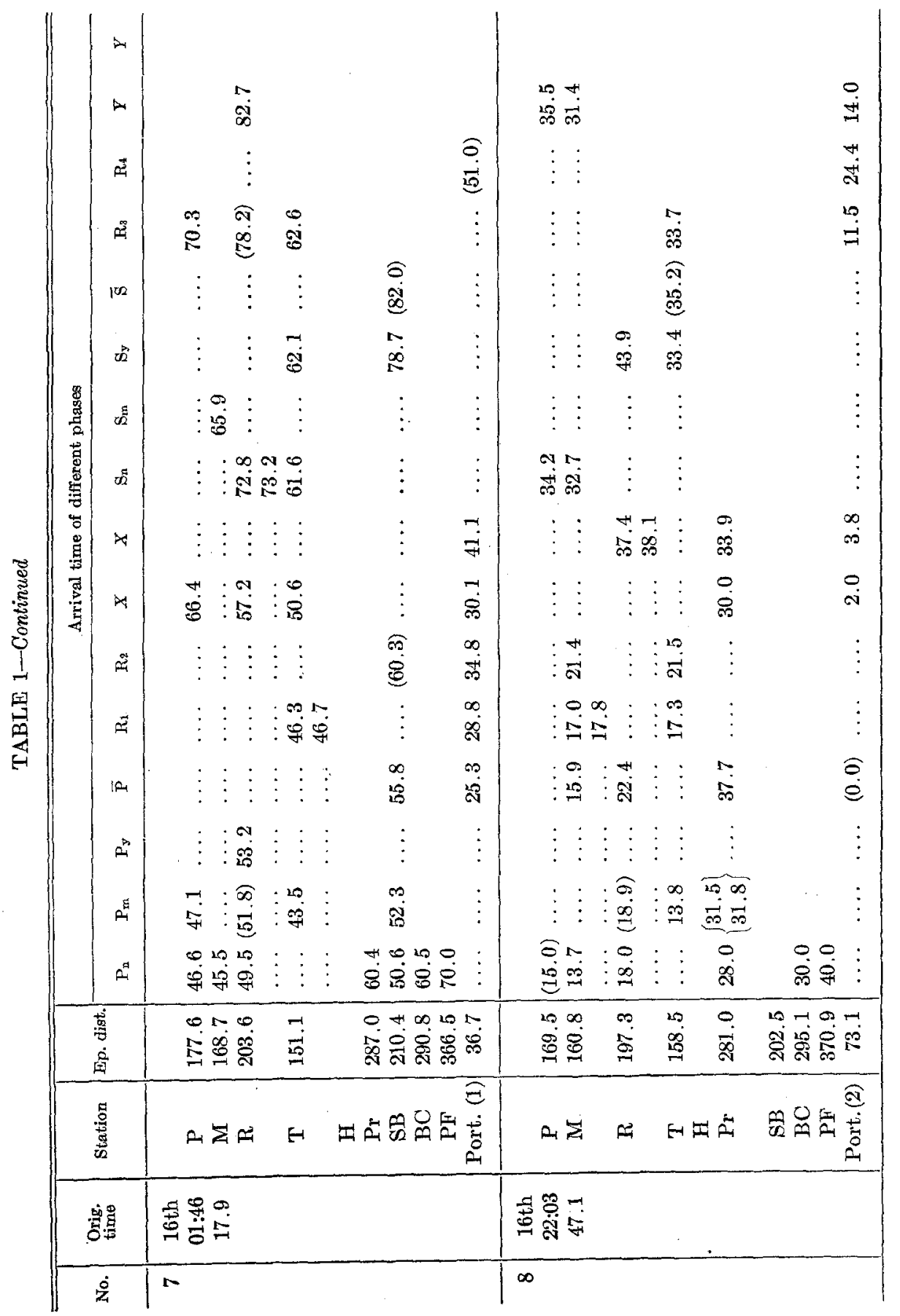


THE WALKER PASS EARTHQUAKES

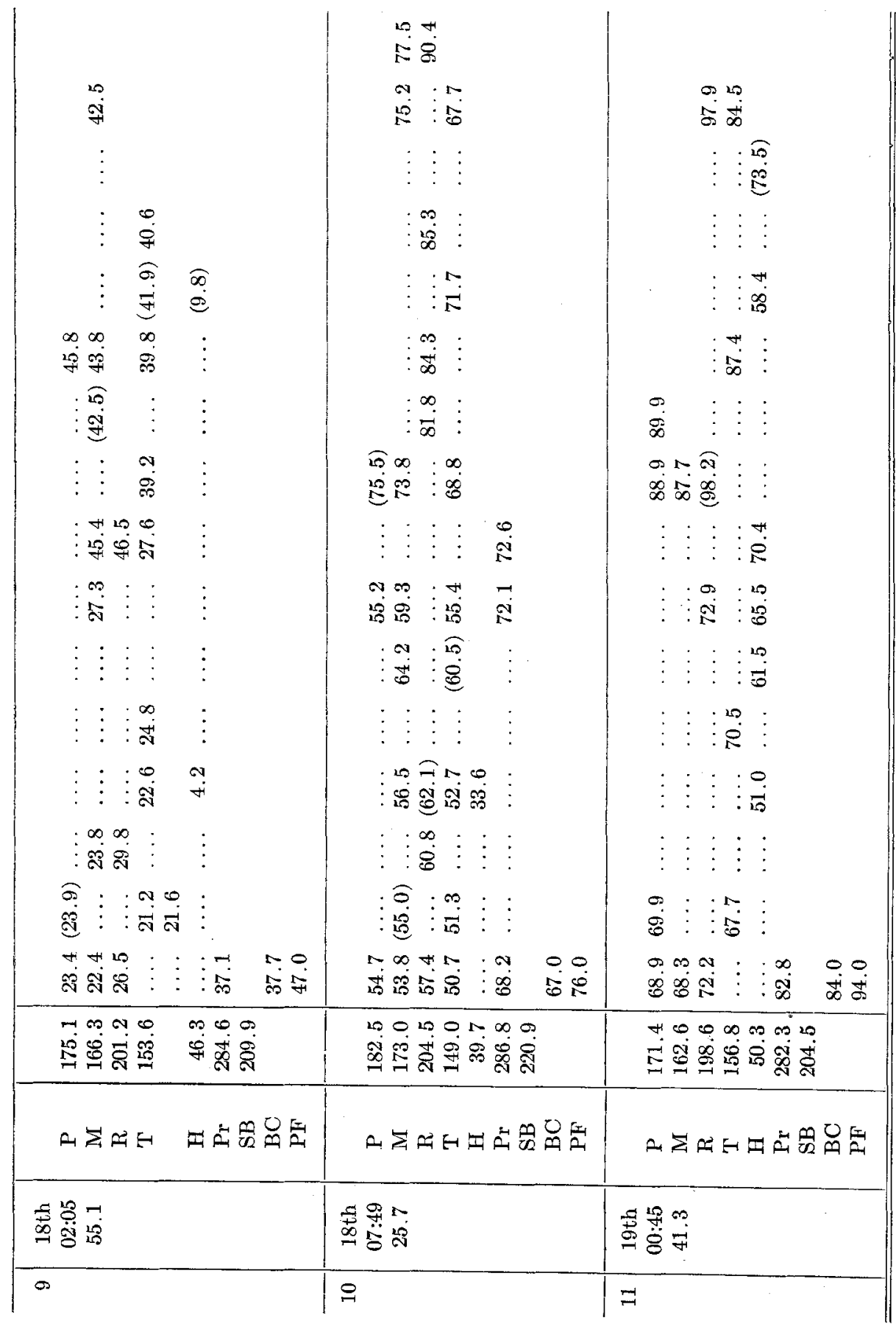




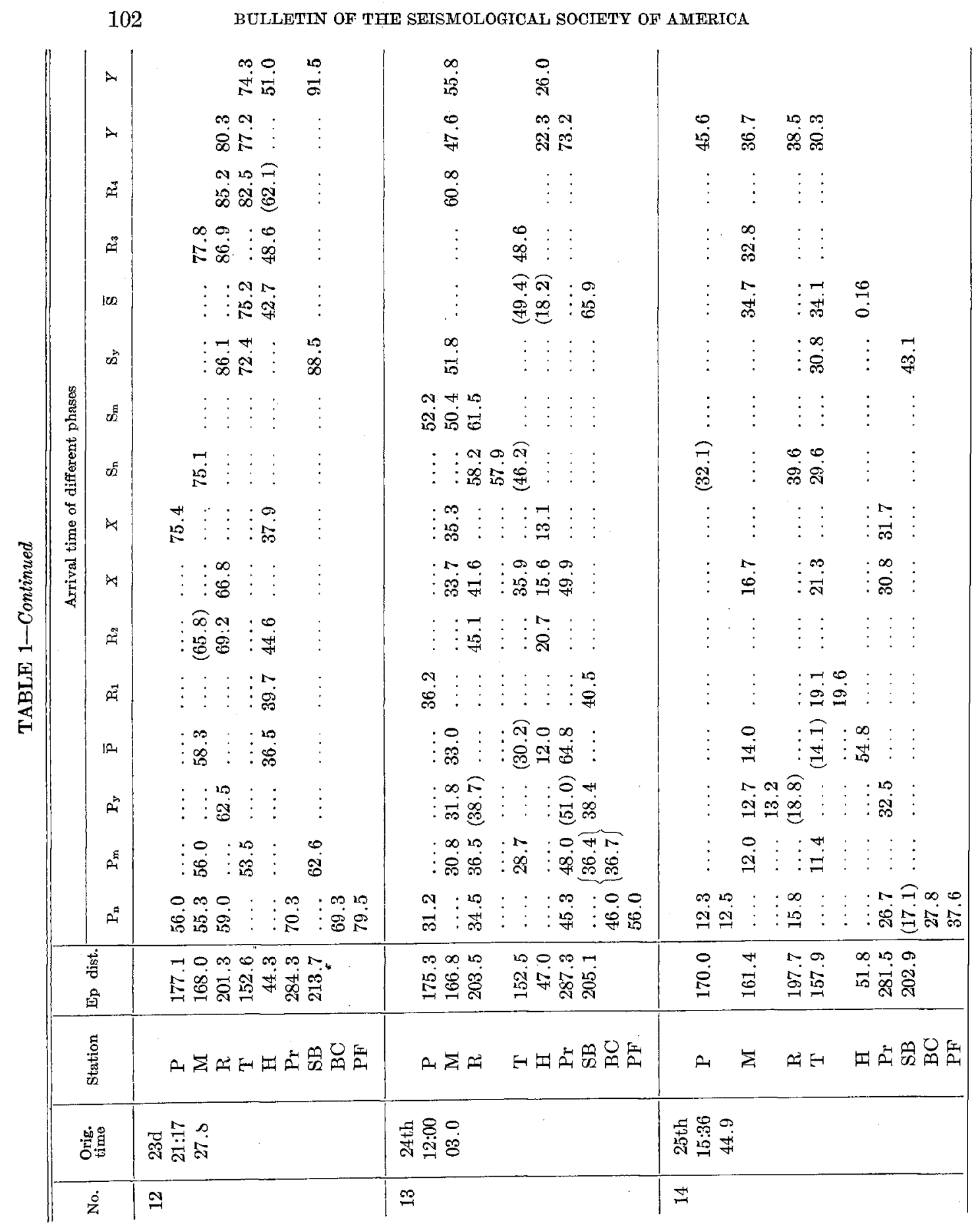


THE WALKER PASS EARTHQUAKES

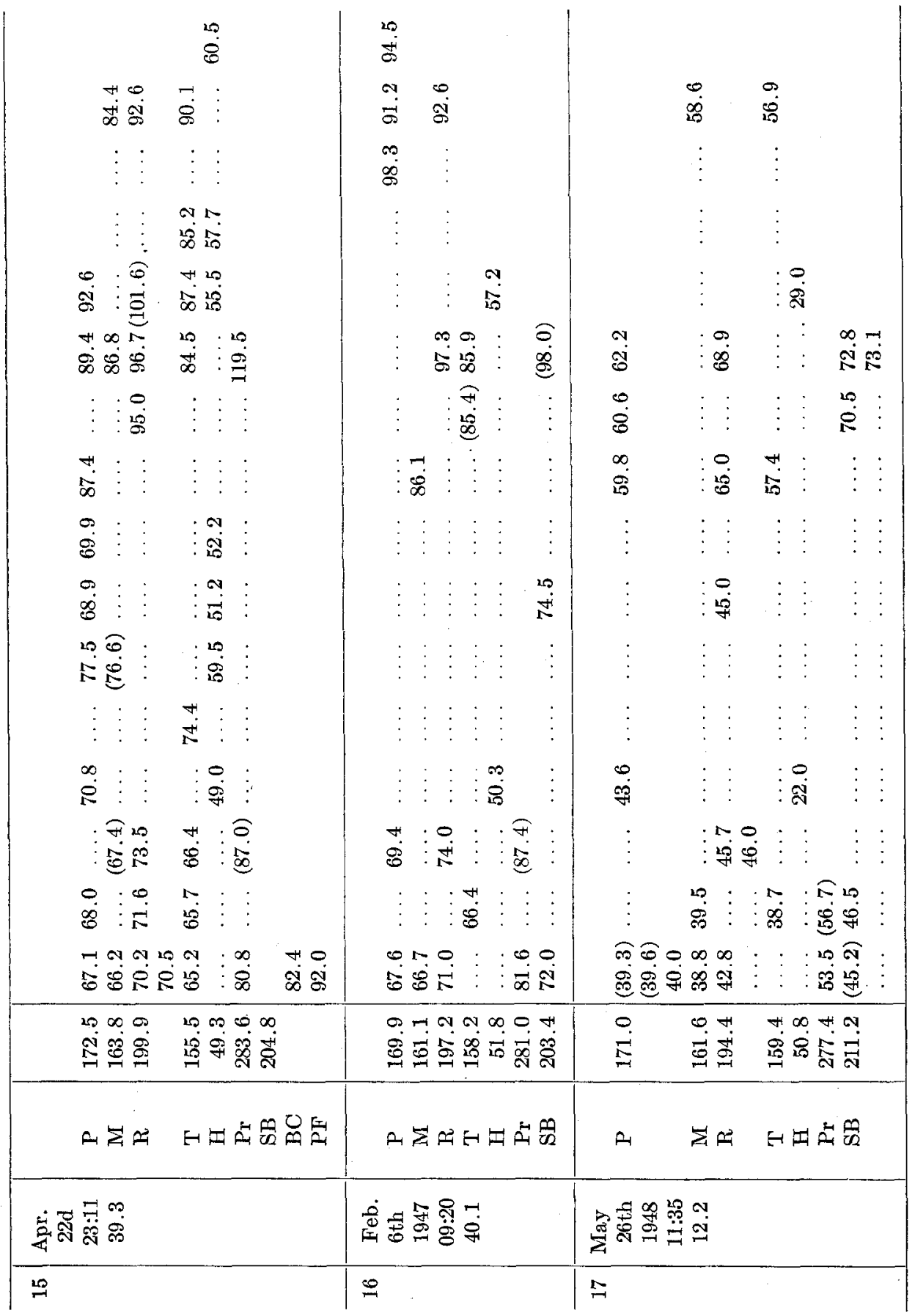




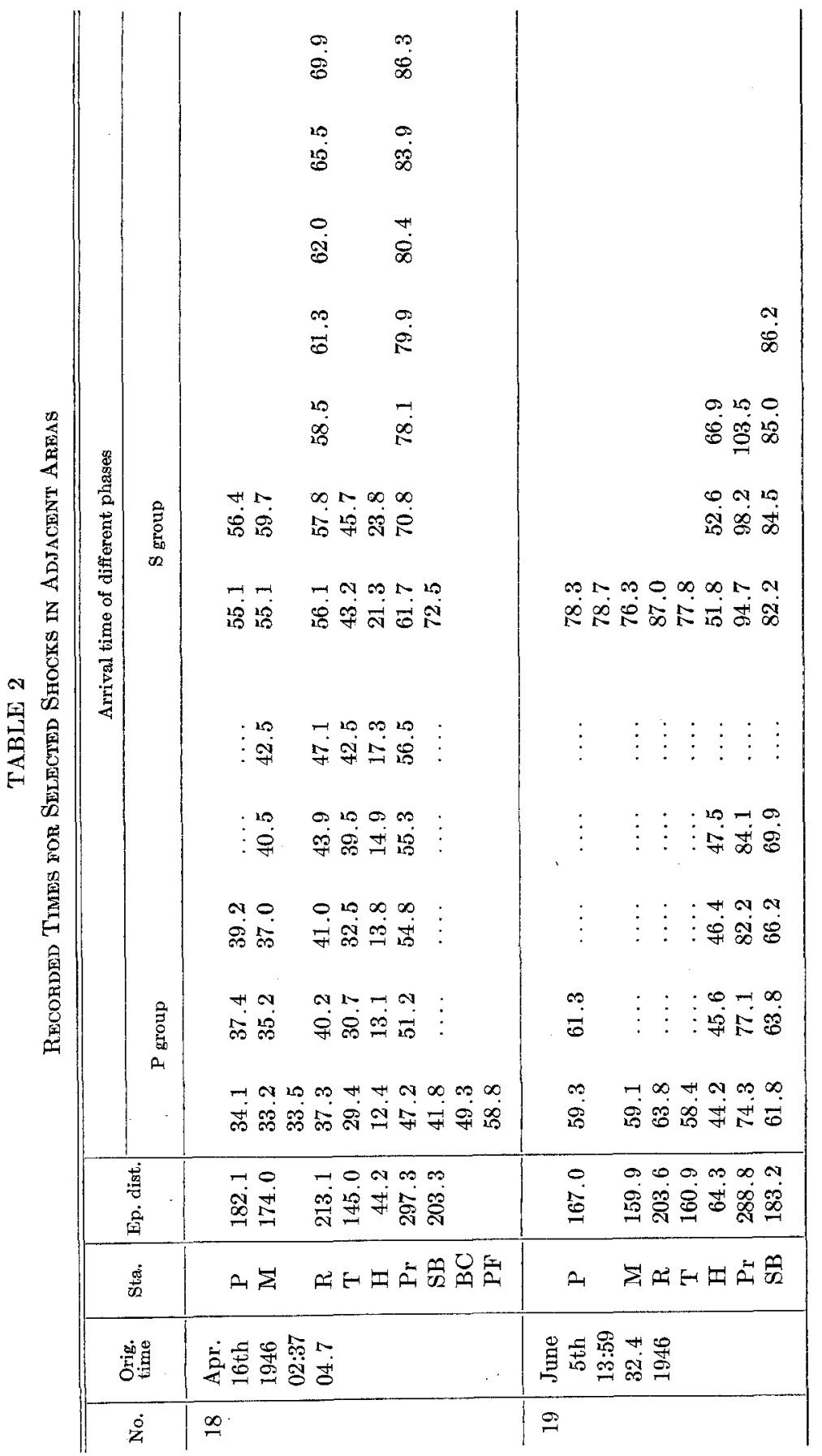




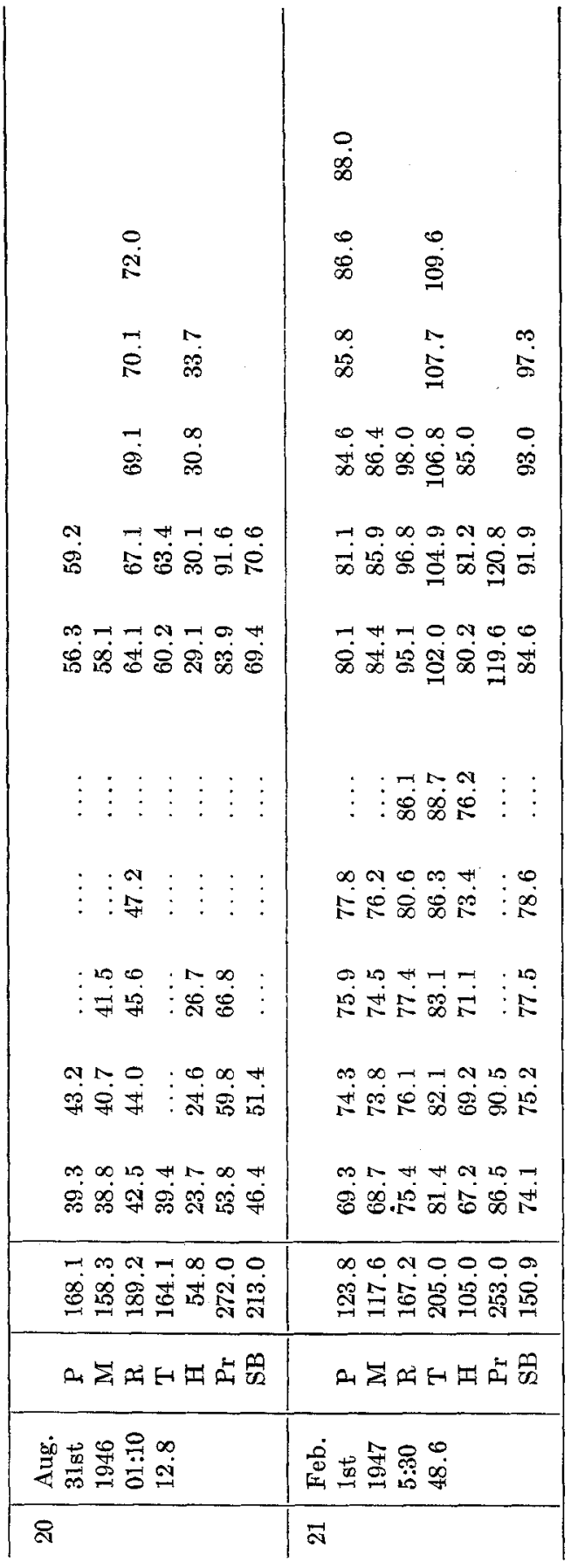


TABLE 3

Eptcenters, Origix Times, and Magnitudes

\begin{tabular}{|c|c|c|c|c|c|c|}
\hline \multirow{2}{*}{ No. } & \multicolumn{2}{|c|}{ Epicenter } & \multicolumn{2}{|c|}{ Coördinates referred to no.(2) } & \multirow{2}{*}{$\underset{\text { Orime }}{\text { Origin }}$} & \multirow{2}{*}{ Magn. } \\
\hline & Lat. (N) & Long. (W) & $x(E)$ & $Y(\mathrm{~N})$ & & \\
\hline 1 & $35^{\circ} 45^{\prime} 20$ & $117^{\circ} 59: 18$ & $\begin{array}{l}\text { km. } \\
6.18\end{array}$ & $\begin{array}{l}\mathrm{km} . \\
3.12\end{array}$ & 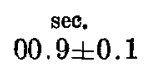 & 5.2 \\
\hline 2 & $43 ! 51$ & $188^{\circ} 3 ! 28$ & & & $35.9 \pm 0.1$ & 6.3 \\
\hline 3 & $42 ! 89$ & $4: 44$ & -1.76 & -1.35 & 35.4 & 5.3 \\
\hline 4 & $46 ! 69$ & $3: 04$ & 0.36 & 5.88 & 09.2 & 4.4 \\
\hline 5 & $42: 86$ & $117^{\circ} 58^{\prime} .63$ & 7.01 & -1.20 & 53.6 & 5.4 \\
\hline 6 & $45^{\prime} 08$ & $118^{\circ} \quad 1^{\prime} .74$ & 2.31 & 2.90 & 33.4 & 5.2 \\
\hline 7 & $44 ! 70$ & $2 ! 33$ & 1.43 & 2.19 & 17.9 & 5.1 \\
\hline 8 & $40 ! 46$ & 4.69 & -2.14 & -5.64 & 47.1 & 4.4 \\
\hline 9 & $43 ! 41$ & $2^{\prime}, 08$ & 1.80 & -0.20 & 55.1 & 4.9 \\
\hline 10 & $46: 83$ & $117^{\circ} 55 ! 27$ & 12.08 & 6.14 & $25.7 \pm 0.1$ & 4.8 \\
\hline 11 & $41: 45$ & $118^{\circ} 3 ! 97$ & 1.05 & -3.81 & 41.3 & 3.5 \\
\hline 12 & $44: 27$ & $117^{\circ} 58: 87$ & 6.64 & 1.40 & $27.8 \pm 0.2$ & 4.1 \\
\hline 13 & $43 ! 66$ & $118^{\circ} 5.93$ & -4.00 & 0.28 & 03.0 & 4.5 \\
\hline 14 & $40 ! 75$ & $4 ! 62$ & -2.03 & -5.11 & 44.9 & 4.3 \\
\hline 15 & $42 ! 07$ & $4 ! 38$ & -1.66 & -2.67 & 39.3 & 3.9 \\
\hline 16 & $40 ! 64$ & $118^{\circ} 4 ! .02$ & -1.12 & -5.31 & 40.1 & 4.6 \\
\hline 17 & $40: 77$ & $117^{\circ} 57^{\prime} .29$ & 9.02 & -5.08 & 12.2 & 4.1 \\
\hline 18 & $47: 36$ & $118^{\circ} 12^{\prime} \cdot 27$ & -13.56 & 7.11 & 04.7 & 4.1 \\
\hline 19 & $38: 81$ & $20 \prime 68$ & -26.24 & -8.69 & 32.4 & 4.3 \\
\hline 20 & $38: 77$ & $117^{\circ} 53 ! 73$ & 14.39 & -8.77 & 12.8 & 4.2 \\
\hline 21 & $15: 01$ & $118^{\circ} 23 ! 24$ & -30.11 & -52.71 & 48.6 & 3.5 \\
\hline
\end{tabular}

Recorded directions of first motion for shocks 1 and 2 (the large foreshock and the main earthquake) are as follows (c, compression; d, dilatation):

$\begin{array}{cccccccccc}\text { Station } & \text { P } & \text { MW } & \text { R } & \text { T } & \text { II } & \text { Pr } & \text { SB } & \text { BC } & \text { PF } \\ \text { Shock } 1 \ldots \ldots \ldots \ldots & \text { d } & \text { d } & \text { c } & \text { d } & \text { d } & \text { d } & \text { c } & \text { c } & \text { c } \\ \text { Shock } 2 \ldots \ldots \ldots \ldots & \text { d } & \text { d } & \text { d? } & \text { d } & \text { d } & \text { ? } & \text { c? } & \text { c } & \text { c }\end{array}$

The writers are indebted to Professor Gutenberg for valuable discussion and helpful suggestions in carrying out this investigation.

\section{Summary}

The principal earthquake in the Walker Pass region on March 15, 1946, is located at $35^{\circ} 43 ! 5 \mathrm{~N}, 118^{\circ} 03: 3 \mathrm{~W}$, at a depth of $22 \mathrm{~km}$., with origin time at 05:49:35.9 P.S.T. Epicenters of aftershocks scatter about this, with some indication of a NNE-SSW trend. The observed times fit a structure with layers $21.7 \mathrm{~km}$., $9.7 \mathrm{~km}$., and $10.7 \mathrm{~km}$. thick. Velocities of the longitudinal 
and transverse waves agree with those previously determined by Gutenberg for southern California. The effect of the "root" of the Sierra Nevada is seen in the failure of Pn to record at Tinemaha, although it appears there on the seismograms of shocks east and west of the principal group.

California Institute of Technologr, Pasadena, Californta.

(Balch Graduate School of the Geological Sciences, contribution no. 474.) 